\title{
Phase I and pharmacologic study of BNP7787, a novel chemoprotector in patients with advanced non-small cell lung cancer
}

\author{
Noriyuki Masuda $\cdot$ Shunichi Negoro $\cdot$ Frederick Hausheer $\cdot$ Kazuhiko Nakagawa \\ Kaoru Matsui · Shinzoh Kudoh · Koji Takeda • Nobuyuki Yamamoto · \\ Naruo Yoshimura $\cdot$ Yasuo Ohashi $\cdot$ Masahiro Fukuoka
}

Received: 24 December 2009 / Accepted: 18 April 2010 / Published online: 15 May 2010

(C) The Author(s) 2010. This article is published with open access at Springerlink.com

\begin{abstract}
Purpose We conducted a phase I trial of BNP7787 (disodium 2,2'-dithio-bis-ethane sulfonate, Tavocept ${ }^{\mathrm{TM}}$ ), a novel chemoprotective and antitumor enhancing agent administered in combination with paclitaxel and cisplatin. The primary aim was to determine a safe and potentially efficacious BNP7787 dose for preventing and mitigating paclitaxel- and cisplatin-induced toxicities and to evaluate for preliminary evidence of efficacy of treatment.

Patients and methods Twenty-two patients with stage IIIB/IV non-small cell lung cancer (NSCLC) received BNP7787 alone 1 week before co-administration of BNP7787 with paclitaxel followed by cisplatin. Twentyone patients were treated with BNP7787 in escalating doses of $4.1-41.0 \mathrm{~g} / \mathrm{m}^{2}$ concurrently with paclitaxel $175 \mathrm{mg} / \mathrm{m}^{2}$ and cisplatin $75 \mathrm{mg} / \mathrm{m}^{2}$ every 3 weeks.
\end{abstract}

N. Masuda $(\bowtie)$

Department of Respiratory Medicine,

Kitasato University School of Medicine,

Minami-ku, Kitasato, Sagamihara, Japan

e-mail: masuda@med.kitasato-u.ac.jp

S. Negoro

Department of Medical Oncology,

Hyogo Cancer Center, Hyogo, Japan

F. Hausheer

BioNumerik Pharmaceuticals Inc, CEO,

San Antonio, TX, USA

K. Nakagawa $\cdot$ M. Fukuoka

Department of Medical Oncology,

Kinki University School of Medicine, Osaka, Japan

K. Matsui

Department of Thoracic Malignancy,

Medical Center for Respiratory and Allergic Diseases of Osaka

Prefecture, Osaka, Japan
Results The appropriate dose was determined to be $18.4 \mathrm{~g} / \mathrm{m}^{2}$ of BNP7787 although no dose-limiting toxicity was observed up to $41.0 \mathrm{~g} / \mathrm{m}^{2}$. Mild intravenous site discomfort, thirst, and nausea were the most common toxicities. One patient developed grade 2 skin rash, which was severe enough to preclude further study treatment. The $\mathrm{AUC}_{0 \text {-inf }}$ of the metabolite mesna was approximately $6.3 \%$ of the $\mathrm{AUC}_{0 \text {-inf }}$ of BNP7787. Co-administration of paclitaxel and cisplatin did not appear to influence the pharmacokinetics of BNP7787 and mesna. The overall response rate was encouraging; $43 \%$ including 11 patients with prior chemotherapy.

Conclusions The recommended dose for phase II/III studies is $18.4 \mathrm{mg} / \mathrm{m}^{2}$ of BNP7787 in combination with paclitaxel and cisplatin. Further studies are warranted to assess whether BNP7787 prevents and mitigates common and

S. Kudoh $\cdot$ N. Yoshimura

Department of Respiratory Medicine,

Osaka City Medical School, Osaka, Japan

K. Takeda

Department of Clinical Oncology, Osaka City General Hospital,

Osaka, Japan

N. Yamamoto

Department of Respiratory Medicine, Shizuoka Cancer Center,

Shizuoka, Japan

Y. Ohashi

Department of Biostatistics, School of Public Health,

The University of Tokyo, Tokyo, Japan 
serious paclitaxel- and cisplatin-related side effects and enhances the efficacy of paclitaxel and cisplatin in advanced NSCLC patients.

Keywords Chemoprotector $\cdot$ BNP7787 $\cdot$ Mesna .

Phase I study · Lung cancer

\section{Introduction}

Lung cancer is the leading cause of cancer-related deaths in most industrialized countries. Platinum-containing doublets have emerged as the standard of care for the first-line treatment of advanced non-small cell lung cancer (NSCLC) [15]. However, many medical oncologists have not routinely used cisplatin-based chemotherapy to treat patients with advanced NSCLC because of serious side effects, such as cisplatin nephrotoxicity and other toxicities. Chemotherapyinduced neuropathy is also a major dose-limiting side effect of many commonly used chemotherapeutic agents, including platinum drugs and taxanes [10, 23]. Evidence from randomized controlled trials support that cisplatin-based doublets result in superior survival advantages over carboplatin-based treatment in advanced NSCLC $[5,16]$.

Disodium 2,2'-dithio-bis-ethane sulfonate (BNP7787, Tavocept ${ }^{\mathrm{TM}}$, dimesna) is an investigational new agent that is being developed as a chemoprotector against cisplatinand taxane-induced toxicities and to enhance the antitumor effects of chemotherapy [2, 7-9]. BNP7787 is stable and chemically inert in plasma due to the high $\mathrm{PO}_{2}$ in plasma, presence of a disulfide linkage, and the absence of enzymatic metabolism of disulfides in plasma [7-9, 20]. In nonclinical studies, BNP7787 has been observed to distribute to the kidney, gastrointestinal tract, bone marrow, and neuronal cells, and it is further postulated that a substantial proportion of BNP7787 undergoes non-enzymatic conversion to mesna, one of its metabolites, as well as mixed disulfides which are also pharmacologically active $[7-9,11,20]$. In preclinical studies, a high concentration of BNP7787 and active disulfide metabolites as well as mesna that are generated in the kidney which can provide significant nephroprotection mediated by pharmacologically active mixed disulfides that inhibit gamma-glutamyl transpeptidase toxification, which is postulated to be an underlying major mechanism of cisplatin renal toxicity $[11,20]$. In addition, BNP7787 administration can provide nephroprotection by locally inactivating mono-hydrated cisplatin by the formation of non-toxic thioplatinum complexes [11]. Similar cytoprotective effects by BNP7787 have been observed for toxicities associated with paclitaxel and carboplatin $[4,8,9]$.

Based on the promising preclinical results of BNP7787, a phase I trial was carried out in patients with advanced
NSCLC. The objectives of this phase I study were $(a)$ to identify a safe dose of BNP7787 alone and in combination with cisplatin and paclitaxel; $(b)$ to describe and quantify the clinical toxicities of BNP7787; $(c)$ to determine the pharmacokinetics of BNP7787 and one of its active metabolites, mesna; and $(d)$ to obtain preliminary evidence of therapeutic activity in patients with advanced NSCLC.

\section{Patients and methods}

\section{GCP compliance}

This phase I clinical trial in Japan was conducted in accordance with (1) World Medical Association Declaration of Helsinki: Recommendations Guiding Medical Doctors in Biomedical Research Involving Human Subjects (1996), (2) the Japanese Pharmaceutical Affairs Law and Guidelines for Implementation of Clinical Studies for Drugs (Japanese GCP).

\section{Patient selection}

Patients were enrolled in this study if they met all of the following criteria: histologic or cytologic diagnosis of NSCLC; no surgery within 2 weeks, no radiotherapy or chemotherapy within 3 weeks prior to study entry (within 6 weeks for nitrosourea or mitomycin C); a measurable or evaluable lesion; a performance status of 0 or 1 on the Eastern Cooperative Oncology Group (ECOG) scale; adequate bone marrow function (leukocyte count, 4,000 $120,000 / \mu \mathrm{L}$; neutrophil count $\geq 1,500 / \mu \mathrm{L}$; platelet count $\geq 100,000 / \mu \mathrm{L}$ ), normal hepatic function (bilirubin $<1.5 \times$ the upper limit of normal; aspartate amino-transferase (AST) and alanine amino-transferase (ALT) levels $<2.5 \times$ the upper limit of normal), and renal function (creatinine $\leq$ the upper limit of normal and creatinine clearance $\geq 60 \mathrm{~mL} / \mathrm{min}$ ); between 20 and 74 years of age; written informed consent to the study. Patients were ineligible if they had serious infectious diseases or other severe complications (interstitial pneumonia, uncontrollable diabetes or hypertension); atrial fibrillation, serious arrhythmias, or uncontrollable heart failure in previous 6 months; massive pleural or pericardial effusion; symptomatic brain metastases; active concurrent malignancies; lactating or pregnant women, or those attempting to become pregnant; men not willing to use contraception; hearing impairment or neuropathy; had a history of a drug allergy (alcohol, cremophor, etc.); had other medical problems severe enough to prevent compliance with the protocol. The study was approved in advance by the Institutional Review Board and by the Hospital Ethics Committee. 
Dosage, dose escalation procedure and drug administration

BNP7787 was supplied from BioNumerik Pharmaceuticals, Inc., San Antonio, TX as a lyophilized powder containing 2 or $10 \mathrm{~g}$ of the formulated drug. The starting dose of BNP7787 was $4.1 \mathrm{~g} / \mathrm{m}^{2}$. This starting dose was based on the analysis and calculation of a BNP7787: cisplatin $=50: 1$ molar ratio derived from the demonstration of partial cisplatin nephroprotection in rats and elucidating this important relationship to formulate and justify a safe starting dose in humans [7], as well as prior safety data from phase I clinical trials. Dose escalation steps of BNP7787 in cohorts of at least three patients each according to the protocol were 8.2, $12.3,18.4,27.6$, and $41.0 \mathrm{~g} / \mathrm{m}^{2}$. The highest dose tested was justified based on prior non-clinical GLP safety studies, and phase I clinical trials. In the event of dose-limiting toxicity in one patient at any dose level, a maximum of three additional patients would be treated. BNP7787 was given as a single agent by a 30-min intravenous (iv) infusion 1 week prior to chemotherapy so that pharmacokinetic data on BNP7787 alone could be collected and compared and again on day 1. On treatment day 1, paclitaxel dissolved in $500 \mathrm{~mL}$ saline was administered intravenously over $3 \mathrm{~h}$ at a dose of $175 \mathrm{mg} / \mathrm{m}^{2}$. Immediately following paclitaxel administration, the calculated dosage of BNP7787 for the given dose level (in a minimum volume of $100 \mathrm{~mL}$ ) was administered intravenously over 30-45 min, which was immediately followed by intravenous cisplatin $75 \mathrm{mg} / \mathrm{m}^{2}$ in $500 \mathrm{~mL}$ of normal saline administered over $1 \mathrm{~h}$. Study treatment was administered every 3 weeks (one cycle). Prophylactic medications to prevent hypersensitivity reactions to paclitaxel were administered, including iv dexamethasone $20 \mathrm{mg}$ at 12 and $6 \mathrm{~h}$ prior to paclitaxel infusion, and diphenhydramine $50 \mathrm{mg}$ po and ranitidine $50 \mathrm{mg}$ iv $30 \mathrm{~min}$ before paclitaxel administration for paclitaxel hypersensitivity prophylaxis. Patients received $1.6 \mathrm{~L}$ of normal saline and/or electrolyte maintenance fluid prior to BNP7787 administration. Cisplatin was dissolved and infused along a program of forced diuresis that included at least $1.0 \mathrm{~L}$ of normal saline and/or electrolyte maintenance fluid, $300 \mathrm{~mL}$ of $20 \%$ mannitol and furosemide $20 \mathrm{mg}$ iv. Prophylactic antiemetics during and after cisplatin administration consisted of granisetron and dexamethasone.

Patients with evidence of disease progression or those who experienced intolerable toxicity were removed from the study treatment.

\section{Pharmacokinetics}

\section{Sample collection}

A volume of $5 \mathrm{~mL}$ sample of blood was obtained immediately preceding the BNP7787 treatment, $20 \mathrm{~min}$ before the end of the BNP7787 infusion, 10 min before the end of the BNP7787 infusion, at the end of the infusion, and at 0.25 , $0.5,1.0,2.0,4.0,6.0$, and $24 \mathrm{~h}$ after infusion 1 week prior to chemotherapy and day 1 of chemotherapy. The blood samples were transported to the laboratory on ice. Ethylenediaminetetraacetic acid blood samples were centrifuged at room temperature for $1 \mathrm{~min}$ at $10,000 \mathrm{rpm}$. Plasma was separated and immediately deproteinized by adding methanol. All samples were stored frozen at $-20^{\circ} \mathrm{C}$ until analysis.

\section{LC/MS/MS assay}

The samples for pharmacokinetic were shipped on dry ice to keep the specimens frozen during shipment to the laboratory. The total amount of BNP7787 and mesna was determined by a validated method using liquid chromatographic-tandem mass spectrometry (LC/MS/MS) at Nemoto Science Co., (Tokyo, Japan; a Finnigan TSQ7000 mass spectrometer (Thermo Electron Co., USA) equipped with an electrospray ionization (ESI) source was used for all measurements. The HPLC separations were performed with a Waters 2690 Separation module (Waters, Milford, MA, USA), using a Mightysil RP-18 GP (3.0 × 150 mm; Kanto Chemical Co., Tokyo, Japan). The system was operated using LCQUAN software (version 1.2; Thermo Electron). The mobile phase was $10 \mathrm{mmol} / \mathrm{L}$ ammonium acetate $(\mathrm{pH}$ 6.0) at a flow rate of $0.3 \mathrm{~mL} / \mathrm{min}$. The ion transfer capillary temperature was $25^{\circ} \mathrm{C}$, the nitrogen sheath gas flow rate 80 psi, and the auxiliary gas flow rate setting 15 units. The mass spectra were obtained in a selective reaction monitoring (SRM) mode via negative ESI interface within a range of m/z 141-281 (BNP7787), 81-141 (mesna), respectively. The lower limit of quantification (LLQ) for BNP7787 and mesna was 1.00 and $0.10 \mu \mathrm{g} / \mathrm{mL}$, respectively. The intraassay precision and accuracy were satisfactory. Precision was less than 7.1 and $10.0 \%$, accuracy was ranged from -7.0 to $3.7 \%$ ( $-16 \%$ at LLQ) and -4.2 to $2.0 \%$ for BNP7787 and mesna, respectively. Inter-assay precision was less than 7.9 and $10.0 \%$, accuracy ranged from -10.0 to $7.4 \%$ and -6.7 to $2.6 \%$ for BNP7787 and mesna, respectively. The contribution ratio $\left(r^{2}\right)$, calculated using $1 / \mathrm{X}$ weighed regression analysis were higher than 0.99 for both compounds.

\section{Pharmacokinetic analyses}

The following pharmacokinetic parameters of BNP7787 and mesna were estimated using WinNonlin Version 2.1 (Pharsight Corporation, Mountain View, CA). $\mathrm{C}_{\max }$ was the maximum drug concentration, and $\mathrm{T}_{\max }$ was the elapsed time to reach $\mathrm{C}_{\max }$ after the intravenous infusion. $\mathrm{AUC}_{0 \text {-inf }}$ was area under the concentration-time curve calculated by 
Table 1 Patient characteristics

\begin{tabular}{ll}
\hline Total no. of patients & 22 \\
Sex & \\
Male & 15 \\
Female & 7 \\
Age: median (range) & 59.5 years (38-74) \\
Performance status (ECOG) & \\
0 & 6 \\
1 & 16 \\
Previous treatment & \\
Chemotherapy & 9 \\
Chemotherapy + radiotherapy & 2 \\
Surgery & 3 \\
Surgery + radiotherapy & 1 \\
None & 7 \\
No. of prior chemotherapy regimens & \\
Median & 1 \\
Range & $0-2$ \\
Stage & \\
IIIB & 4 \\
IV & 18 \\
Histology & \\
Adenocarcinoma & \\
Squamous cell carcinoma & \\
Large cell carcinoma & \\
Adenosquamous cell carcinoma & \\
\hline
\end{tabular}

global summation of the linear trapezoidal rule from time zero up to the last measurable data point at $24 \mathrm{~h}$ post administration with extrapolation to infinity. The elimination rate constant $(\lambda \mathrm{z})$ was determined by log-linear regression analysis of the terminal phase of the plasma concentration-time curves. The terminal half-life $\left(T_{1 / 2}\right)$ was calculated by the equation: $\mathrm{T}_{1 / 2}=\ln 2 / \lambda \mathrm{z}$. The mean residence time (MRT) was calculated by the equation of AUMC (area under the first moment - time curve)/AUC - [infusion time]/2. Clearance (CL) was calculated by dividing the actual dose received by the AUC. The volume of distribution at steady state $\left(\mathrm{Vd}_{\mathrm{ss}}\right)$ was calculated by the equation of $\mathrm{CL} \times \mathrm{MRT}$.

\section{Evaluation}

Tumors were staged based on a complete medical history and physical examination, routine chest radiography, bone scintiscanning, computed tomography (CT) of the chest and abdomen, whole-brain magnetic resonance imaging (MRI) or CT scan, and fiberoptic bronchoscopy. Staging was performed according to previous TNM criteria [14]. Prior to the first course of treatment, a complete blood count (including a differential white cell count and platelet count), biochemistry tests (including renal function, hepatic function, and electrolytes), electrocardiogram, and urinalysis were performed. Complete blood count and biochemistry tests were repeated at least twice a week after this initial evaluation, while the other investigations were repeated at least every 6 weeks to evaluate the target lesions. A complete blood count was repeated every day until recovery, when ANC $<500 / \mu 1$, leukocyte count $<1,000 / \mu 1$, or platelet count $<10,000 / \mu \mathrm{l}$ was observed during the first cycle of treatment. Adverse events were recorded and graded using the National Cancer Institute Common Toxicity Criteria, Version 2.0. Tumor response was classified in accordance with WHO criteria [13].

\section{Results}

Between April 2000 and December 2001, 22 patients participated in this trial. Demographics of the study patient population are shown in Table 1. Seven patients were women and fifteen were men, and the median age was 59.5 years (range: 38-74 years) with a median performance status of 1 . Dosing information is shown in Table 2. In this study, a total of 74 cycles of BNP7787 were administered. The number of treatment cycles administered per patient ranged from 1 to 4 (1 cycle in 1 patient, 2 in 4 patients, 3 in 3 patients, and 4 in 14 patients). One patient developed grade 2 skin rash after

Table 2 Dose escalation scheme and treatment administered to patients

\begin{tabular}{|c|c|c|c|c|c|c|}
\hline \multirow[t]{2}{*}{ Dose level } & \multirow[t]{2}{*}{ No. of patients } & \multicolumn{2}{|l|}{ BNP7787 } & \multicolumn{3}{|l|}{ Chemotherapy } \\
\hline & & Dose $\left(\mathrm{g} / \mathrm{m}^{2}\right)$ & Total no. of cycles & Paclitaxel $\left(\mathrm{mg} / \mathrm{m}^{2}\right)$ & Cisplatin $\left(\mathrm{mg} / \mathrm{m}^{2}\right)$ & Total no. of cycles \\
\hline 1 & 3 & 4.1 & 10 & 175 & 75 & 7 \\
\hline 2 & 6 & 8.2 & 18 & 175 & 75 & 12 \\
\hline 3 & 4 & 12.3 & 13 & 175 & 75 & 9 \\
\hline 4 & 3 & 18.4 & 12 & 175 & 75 & 9 \\
\hline 5 & 3 & 27.6 & 9 & 175 & 75 & 6 \\
\hline 6 & 3 & 41.0 & 12 & 175 & 75 & 9 \\
\hline
\end{tabular}


Table 3 Worst toxicities due to single agent BNP7787 administration at all dose levels

\begin{tabular}{|c|c|c|c|c|c|c|c|c|c|c|c|c|c|c|c|c|c|c|c|c|c|c|c|c|}
\hline \multirow[t]{4}{*}{ Side effects } & \multicolumn{24}{|c|}{ Dose of BNP7787 $\left(\mathrm{g} / \mathrm{m}^{2}\right)$} \\
\hline & \multirow{2}{*}{\multicolumn{4}{|c|}{$\begin{array}{l}4.1(n=3) \\
\text { Grade }\end{array}$}} & \multirow{2}{*}{\multicolumn{4}{|c|}{$\begin{array}{l}8.2(n=6) \\
\text { Grade }\end{array}$}} & \multirow{2}{*}{\multicolumn{4}{|c|}{$\frac{12.3(n=4)}{\text { Grade }}$}} & \multirow{2}{*}{\multicolumn{4}{|c|}{$\frac{18.4 n=(3)}{\text { Grade }}$}} & \multirow{2}{*}{\multicolumn{4}{|c|}{$\frac{27.6(n=3)}{\text { Grade }}$}} & \multicolumn{4}{|c|}{$41.0(n=3)$} \\
\hline & & & & & & & & & & & & & & & & & & & & & & & & \\
\hline & 1 & 2 & 3 & 4 & 1 & 2 & 3 & 4 & 1 & 2 & 3 & 4 & 1 & 2 & 3 & 4 & 1 & 2 & 3 & 4 & 1 & 2 & 3 & 4 \\
\hline $\begin{array}{l}\text { Local iv site discomfort } \\
\quad \text { (injection site pain and reaction) }\end{array}$ & 0 & 0 & 0 & 0 & 1 & 0 & 0 & 0 & 1 & 0 & 0 & 0 & 2 & 0 & 0 & 0 & 3 & 0 & 0 & 0 & 3 & 0 & 0 & 0 \\
\hline Thirst & 0 & 0 & 0 & 0 & 0 & 0 & 0 & 0 & 0 & 0 & 0 & 0 & 0 & 0 & 0 & 0 & 0 & 0 & 0 & 0 & 3 & 0 & 0 & 0 \\
\hline $\begin{array}{l}\text { Facial flush } \\
\text { (feeling of warmth, flushing, hot flush) }\end{array}$ & 0 & 0 & 0 & 0 & 0 & 0 & 0 & 0 & 0 & 0 & 0 & 0 & 0 & 0 & 0 & 0 & 1 & 0 & 0 & 0 & 3 & 0 & 0 & 0 \\
\hline Skin rash & 0 & 0 & 0 & 0 & 0 & 1 & 0 & 0 & 0 & 0 & 0 & 0 & 0 & 0 & 0 & 0 & 1 & 0 & 0 & 0 & 0 & 0 & 0 & 0 \\
\hline Numbness & 0 & 0 & 0 & 0 & 0 & 0 & 0 & 0 & 0 & 0 & 0 & 0 & 0 & 0 & 0 & 0 & 1 & 0 & 0 & 0 & 0 & 0 & 0 & 0 \\
\hline Nausea & 0 & 0 & 0 & 0 & 0 & 0 & 0 & 0 & 0 & 0 & 0 & 0 & 0 & 0 & 0 & 0 & 1 & 0 & 0 & 0 & 0 & 0 & 0 & 0 \\
\hline Vomiting & 0 & 0 & 0 & 0 & 0 & 0 & 0 & 0 & 0 & 0 & 0 & 0 & 0 & 0 & 0 & 0 & 1 & 0 & 0 & 0 & 0 & 0 & 0 & 0 \\
\hline Palpitation & 0 & 0 & 0 & 0 & 0 & 0 & 0 & 0 & 0 & 0 & 0 & 0 & 0 & 0 & 0 & 0 & 0 & 0 & 0 & 0 & 1 & 0 & 0 & 0 \\
\hline $\begin{array}{l}\text { Nasal obstruction } \\
\quad \text { (nasal obstruction, rhinitis) }\end{array}$ & 0 & 0 & 0 & 0 & 0 & 0 & 0 & 0 & 0 & 0 & 0 & 0 & 0 & 0 & 0 & 0 & 0 & 0 & 0 & 0 & 2 & 0 & 0 & 0 \\
\hline
\end{tabular}

Table 4 Worst toxicities observed at different dose levels of BNP7787 coadministered with paclitaxel and cisplatin

\begin{tabular}{|c|c|c|c|c|c|c|c|c|c|c|c|c|c|c|c|c|c|c|c|c|c|c|c|c|}
\hline \multirow[t]{4}{*}{ Side effects } & \multicolumn{24}{|c|}{ Dose of BNP7787 $\left(\mathrm{g} / \mathrm{m}^{2}\right)$} \\
\hline & \multicolumn{4}{|c|}{$4.1(n=3)$} & \multicolumn{4}{|c|}{$8.2(n=5)$} & \multicolumn{4}{|c|}{$12.3(n=4)$} & \multicolumn{4}{|c|}{$18.4 n=(3)$} & \multicolumn{4}{|c|}{$27.6(n=3)$} & \multicolumn{4}{|c|}{$41.0(n=3)$} \\
\hline & \multicolumn{4}{|c|}{ Grade } & \multicolumn{4}{|c|}{ Grade } & \multicolumn{4}{|c|}{ Grade } & \multicolumn{4}{|c|}{ Grade } & \multicolumn{4}{|c|}{ Grade } & \multicolumn{4}{|c|}{ Grade } \\
\hline & 1 & 2 & 3 & 4 & 1 & 2 & 3 & 4 & 1 & 2 & 3 & 4 & 1 & 2 & 3 & 4 & 1 & 2 & 3 & 4 & 1 & 2 & 3 & 4 \\
\hline Neutropenia & 0 & 0 & 0 & 2 & 0 & 0 & 0 & 5 & 0 & 0 & 1 & 3 & 0 & 0 & 1 & 2 & 0 & 0 & 1 & 2 & 0 & 0 & 0 & 3 \\
\hline Leukopenia & 0 & 1 & 1 & 0 & 0 & 2 & 3 & 0 & 2 & 0 & 2 & 0 & 1 & 0 & 1 & 0 & 1 & 1 & 1 & 0 & 0 & 2 & 1 & 0 \\
\hline Lymphopenia & 0 & 0 & 0 & 0 & 0 & 1 & 0 & 0 & 0 & 0 & 0 & 0 & 0 & 1 & 0 & 0 & 0 & 1 & 0 & 0 & 0 & 0 & 1 & 0 \\
\hline Anemia (Hb decreased) & 0 & 1 & 0 & 0 & 2 & 0 & 0 & 0 & 0 & 1 & 1 & 0 & 1 & 1 & 0 & 0 & 0 & 1 & 0 & 0 & 3 & 0 & 0 & 0 \\
\hline Thrombocytopenia & 1 & 0 & 0 & 0 & 1 & 0 & 0 & 0 & 0 & 0 & 0 & 0 & 0 & 0 & 0 & 0 & 0 & 0 & 0 & 0 & 0 & 0 & 0 & 0 \\
\hline Neutropenic fever & 0 & 0 & 0 & 0 & 0 & 0 & 1 & 0 & 0 & 0 & 0 & 0 & 0 & 0 & 1 & 0 & 0 & 0 & 1 & 0 & 0 & 0 & 1 & 0 \\
\hline Nausea & 2 & 0 & 0 & 0 & 2 & 2 & 1 & 0 & 0 & 1 & 2 & 0 & 2 & 0 & 1 & 0 & 1 & 2 & 0 & 0 & 1 & 0 & 1 & 0 \\
\hline Vomiting & 0 & 1 & 0 & 0 & 0 & 3 & 1 & 0 & 1 & 0 & 2 & 0 & 0 & 0 & 1 & 0 & 0 & 1 & 0 & 0 & 0 & 0 & 0 & 0 \\
\hline Anorexia & 2 & 0 & 1 & 0 & 1 & 2 & 0 & 0 & 0 & 2 & 1 & 0 & 2 & 0 & 1 & 0 & 1 & 2 & 0 & 0 & 0 & 2 & 1 & 0 \\
\hline Constipation & 0 & 0 & 0 & 0 & 0 & 1 & 1 & 0 & 0 & 0 & 1 & 0 & 0 & 1 & 0 & 0 & 0 & 0 & 0 & 0 & 0 & 1 & 1 & 0 \\
\hline General fatigue & 1 & 0 & 1 & 0 & 2 & 1 & 0 & 0 & 1 & 1 & 0 & 0 & 2 & 1 & 0 & 0 & 2 & 0 & 1 & 0 & 2 & 1 & 0 & 0 \\
\hline Myalgia & 0 & 0 & 0 & 0 & 1 & 1 & 0 & 0 & 0 & 0 & 1 & 0 & 1 & 0 & 0 & 0 & 2 & 0 & 0 & 0 & 1 & 0 & 0 & 0 \\
\hline Arthralgia & 0 & 1 & 0 & 0 & 2 & 2 & 0 & 0 & 1 & 1 & 1 & 0 & 2 & 1 & 0 & 0 & 2 & 0 & 1 & 0 & 1 & 1 & 0 & 0 \\
\hline Alopecia & 2 & 1 & 0 & 0 & 1 & 2 & 0 & 0 & 2 & 2 & 0 & 0 & 0 & 2 & 0 & 0 & 1 & 2 & 0 & 0 & 0 & 3 & 0 & 0 \\
\hline Peripheral neuropathy & 3 & 0 & 0 & 0 & 4 & 0 & 0 & 0 & 1 & 1 & 0 & 0 & 2 & 0 & 0 & 0 & 3 & 0 & 0 & 0 & 2 & 0 & 0 & 0 \\
\hline Increase in creatinine & 0 & 0 & 0 & 0 & 1 & 0 & 0 & 0 & 0 & 0 & 0 & 0 & 0 & 0 & 0 & 0 & 0 & 0 & 0 & 0 & 0 & 0 & 0 & 0 \\
\hline
\end{tabular}

the first course of BNP7787 alone at the level 2; this condition precluded further protocol treatment. A total of 21 patients and 52 cycles of paclitaxel plus cisplatin were administered ( 1 cycle in 4 patients, 2 in 3 patients, and 3 in 14 patients). All treated patients were assessed for BNP7787 toxicity, and 21 patients were assessed for toxicity and response to BNP7787 co-administered with paclitaxel plus cisplatin.
Toxicities

\section{Side effects from BNP7787}

Generally, toxicities related to BNP7787 administration were very mild. No grade 2 or worse toxicity was observed at all dose levels of BNP7787, except for one instance of grade 2 skin rash observed at dose level 2, 



Fig. 1 Plasma concentration-time curves of BNP7787 in patients receiving BNP7787 treatment at dose of $4.1 \mathrm{~g} / \mathrm{m}^{2}$ (filled diamond), $8.2 \mathrm{~g} / \mathrm{m}^{2}$ (filled square), $12.3 \mathrm{~g} / \mathrm{m}^{2}$ (filled triangle), $18.4 \mathrm{~g} / \mathrm{m}^{2}$ (open diamond), $27.6 \mathrm{~g} / \mathrm{m}^{2}$ (open square) and $41.0 \mathrm{~g} / \mathrm{m}^{2}$ (open circle) in alone (a) and in combination with paclitaxel and cisplatin (b). Each point represents the mean of patients. Infusion time was 30 min except for two patients at a dose level of $27.6 \mathrm{~g} / \mathrm{m}^{2}$ and all three patients at dose level of $41.0 \mathrm{~g} / \mathrm{m}^{2}$

which resulted in cessation of protocol treatment in one patient (Table 3 ). The only adverse event encountered at dose levels 1 through 4 was grade 1 local iv site discomfort (injection site pain and reaction) in four of 16 (25.0\%) patients. At dose levels 5 and 6, which represented BNP7787 dose levels of 27.6 and $41.0 \mathrm{~g} / \mathrm{m}^{2}$, all patients experienced transient, reversible grade 1 local iv site discomfort. At the dose level 5, extension of the infusion time from 30 to $45 \mathrm{~min}$ lessened the injection site discomfort. At the highest dose level $\left(41.0 \mathrm{~g} / \mathrm{m}^{2}\right)$, all patients received BNP7787 as a 45-min infusion to lessen the duration, intensity and frequency of injection site pain, based on prior phase I observations [3, 23]. Despite prolongation of the infusion time, all patients complained of discomfort of grade 1 at the local iv infusion site. The local iv site discomfort subsided promptly after completion of the BNP7787 infusion. Other frequently observed BNP7787-related events comprised facial flush (4), thirst (3), nasal obstruction (2), nausea and vomiting (1), and palpitation (1). All these toxicities were grade 1 and disappeared promptly after the end of the infusion.
Side effects from a combination of cisplatin and paclitaxel

Clinically important grade 3/4 non-hematologic toxicities experienced over all courses of treatment included gastrointestinal events of nausea (24\% of patients), anorexia (19\%), vomiting (19\%), and constipation (14\%; Table 4). General fatigue was noted in $10 \%$ of patients. Joint or muscle pain was reported in 10 or $5 \%$, respectively, of patients. Grade 2 peripheral neuropathy was reported in $5 \%$ of patients. No grade 2 or worse renal toxicity was observed in this trial.

The principal grade $3 / 4$ hematologic toxicities were neutropenia (95\% of patients), leukopenia (43\%) and lymphopenia (5\%; Table 4). Grade 3 anemia (5\%) was observed. No grade $3 / 4$ thrombocytopenia was observed in this trial. Grade 3 neutropenic fever was noted in 19\% of patients. There were no treatment-related deaths during the trial. There were no significant influences of the BNP7787 dose on the occurrence of these adverse events when compared to historically similar patients.

\section{Pharmacokinetics}

Plasma samples for BNP7787 were obtained from 22 patients who received BNP7787 alone, and from 21 patients who received BNP7787 in combination with paclitaxel and cisplatin. The plasma concentration-time curves for the different doses of BNP7787 are shown in Fig. 1a, b, and the pharmacokinetic parameters derived from the plotted data are listed in Tables 5 and 6 . The plasma concentrations of BNP7787 reached the $\mathrm{C}_{\max }$ at the end of 30-45 min infusion, and it increased proportionally by the dose. Plasma elimination curves for BNP7787 alone and in combination with chemotherapy were fitted using a onecompartment model with terminal half-life of $0.62-2.33 \mathrm{~h}$ and $0.66-1.67 \mathrm{~h}$, with or without chemotherapy, respectively. Formation of the metabolite mesna was rapidly observed following administration of the parent compound, and the mesna $\mathrm{C}_{\max }$ was reached between 0.5 and $1 \mathrm{~h}$ after the end of the BNP7787 infusion. The plasma concentration of the mesna metabolite decreased more slowly than that of BNP7787 with the half-life of $0.88-6.45 \mathrm{~h}$ and 0.90-6.28 h, respectively (Fig. 2a, b). No significant differences were observed in pharmacokinetic parameters between BNP7787 alone and in combination with chemotherapy. The ratio of $\mathrm{C}_{\max }$ of the metabolite mesna to that of BNP7787 ranged from 1.4 to $4.2 \%$; this observation is consistent with prior observations and predicted by the free thiol hypothesis [9]. The mean $\mathrm{AUC}_{0 \text {-inf }}$ of mesna was approximately $6.2 \%$ of the $\mathrm{AUC}_{0 \text {-inf }}$ of $\mathrm{BNP7787}$. The observed BNP7787 plasma half-life, $\mathrm{Vd}_{\mathrm{ss}}$, CL, and MRT also remained relatively constant over the dose ranges studied, regardless of chemotherapy administration. The 
Table 5 Pharmacokinetic parameters of BNP7787 after administration of BNP7787 alone and BNP7787 in combination with paclitaxel and cisplatin

\begin{tabular}{|c|c|c|c|c|c|c|c|}
\hline \multirow[t]{2}{*}{ Parameter } & \multirow[t]{2}{*}{ Treatment } & \multicolumn{6}{|c|}{ BNP7787 dose $\left(\mathrm{g} / \mathrm{m}^{2}\right)$} \\
\hline & & $4.1(n=3 / 3)^{*}$ & $8.2(n=6 / 5)$ & $12.3(n=4 / 4)$ & $18.4(n=3 / 3)$ & $27.6(n=3 / 3)$ & $41.0(n=3 / 3)$ \\
\hline \multirow{2}{*}{$\mathrm{AUC}_{0-\mathrm{t}}(\mu \mathrm{g} \cdot \mathrm{h} / \mathrm{mL})$} & BNP alone & $499 \pm 79 * *$ & $1,332 \pm 181$ & $1,851 \pm 485$ & $2,748 \pm 496$ & $5,576 \pm 733$ & $8,551 \pm 948$ \\
\hline & $\mathrm{BNP}+\mathrm{CT}$ & $453 \pm 73$ & $1,180 \pm 194$ & $1,545 \pm 320$ & $2,552 \pm 307$ & $5,937 \pm 2,799$ & $6,577 \pm 843$ \\
\hline \multirow[t]{2}{*}{$\mathrm{AUC}_{0 \text {-inf. }}(\mu \mathrm{g} \mathrm{h} / \mathrm{mL})$} & BNP alone & $501 \pm 78$ & $1,347 \pm 194$ & $1,870 \pm 498$ & $2,757 \pm 500$ & $5,780 \pm 981$ & $8,836 \pm 1,267$ \\
\hline & $\mathrm{BNP}+\mathrm{CT}$ & $455 \pm 73$ & $1,194 \pm 209$ & $1,563 \pm 330$ & $2,565 \pm 316$ & $5,974 \pm 2,774$ & $6,845 \pm 1,124$ \\
\hline \multirow[t]{2}{*}{$\mathrm{C}_{\max }(\mu \mathrm{g} / \mathrm{mL})$} & BNP alone & $408 \pm 16$ & $946 \pm 273$ & $1,176 \pm 299$ & $1,864 \pm 127$ & $2,946 \pm 271$ & $4,233 \pm 683$ \\
\hline & $\mathrm{BNP}+\mathrm{CT}$ & $402 \pm 29$ & $702 \pm 113$ & $928 \pm 93$ & $1,627 \pm 148$ & $2,588 \pm 672$ & $3,250 \pm 291$ \\
\hline \multirow[t]{2}{*}{$\mathrm{T}_{1 / 2}(\mathrm{~h})$} & BNP alone & $0.76 \pm 0.11$ & $0.92 \pm 0.19$ & $0.94 \pm 0.13$ & $0.75 \pm 0.07$ & $1.19 \pm 0.43$ & $1.25 \pm 0.38$ \\
\hline & $\mathrm{BNP}+\mathrm{CT}$ & $0.72 \pm 0.09$ & $0.92 \pm 0.19$ & $0.95 \pm 0.17$ & $0.78 \pm 0.16$ & $1.47 \pm 0.75$ & $1.27 \pm 0.52$ \\
\hline \multirow[t]{2}{*}{$\Lambda \mathrm{z}\left(\mathrm{h}^{-1}\right)$} & BNP alone & $0.93 \pm 0.13$ & $0.78 \pm 0.15$ & $0.75 \pm 0.11$ & $0.93 \pm 0.09$ & $0.64 \pm 0.22$ & $0.59 \pm 0.17$ \\
\hline & $\mathrm{BNP}+\mathrm{CT}$ & $0.97 \pm 0.13$ & $0.78 \pm 0.13$ & $0.75 \pm 0.16$ & $0.91 \pm 0.19$ & $0.54 \pm 0.22$ & $0.61 \pm 0.23$ \\
\hline \multirow[t]{2}{*}{$\mathrm{MRT}_{0-\mathrm{t}}(\mathrm{h})$} & BNP alone & $0.88 \pm 0.18$ & $1.18 \pm 0.22$ & $1.28 \pm 0.08$ & $1.11 \pm 0.08$ & $1.46 \pm 0.28$ & $1.52 \pm 0.29$ \\
\hline & $\mathrm{BNP}+\mathrm{CT}$ & $0.83 \pm 0.13$ & $1.22 \pm 0.21$ & $1.29 \pm 0.09$ & $1.21 \pm 0.19$ & $1.92 \pm 0.93$ & $1.50 \pm 0.29$ \\
\hline \multirow[t]{2}{*}{$\operatorname{MRT}_{0 \text {-inf. }}(\mathrm{h})$} & BNP alone & $0.91 \pm 0.17$ & $1.24 \pm 0.28$ & $1.34 \pm 0.11$ & $1.13 \pm 0.09$ & $1.67 \pm 0.52$ & $1.72 \pm 0.50$ \\
\hline & $\mathrm{BNP}+\mathrm{CT}$ & $0.86 \pm 0.13$ & $1.29 \pm 0.28$ & $1.36 \pm 0.11$ & $1.24 \pm 0.21$ & $1.97 \pm 0.89$ & $1.75 \pm 0.59$ \\
\hline \multirow[t]{2}{*}{$\mathrm{Vd}_{\mathrm{ss}}(\mathrm{L})$} & BNP alone & $11.33 \pm 2.36$ & $11.79 \pm 2.95$ & $15.37 \pm 3.34$ & $12.44 \pm 2.42$ & $13.86 \pm 1.67$ & $12.19 \pm 0.92$ \\
\hline & $\mathrm{BNP}+\mathrm{CT}$ & $11.85 \pm 2.43$ & $13.53 \pm 3.45$ & $18.49 \pm 3.94$ & $14.27 \pm 0.52$ & $16.52 \pm 3.52$ & $16.11 \pm 2.30$ \\
\hline \multirow[t]{2}{*}{$\mathrm{CL}(\mathrm{L} / \mathrm{h})$} & BNP alone & $12.57 \pm 1.84$ & $9.59 \pm 2.13$ & $11.66 \pm 3.22$ & $11.20 \pm 2.94$ & $8.77 \pm 2.56$ & $7.40 \pm 1.60$ \\
\hline & $\mathrm{BNP}+\mathrm{CT}$ & $13.83 \pm 2.02$ & $10.69 \pm 2.84$ & $13.70 \pm 3.29$ & $11.75 \pm 2.26$ & $9.55 \pm 4.65$ & $9.71 \pm 2.65$ \\
\hline
\end{tabular}

$A U C_{0-t}$ area under the plasma concentration-time curve up to last measurable point at $24 \mathrm{~h}$ from infusion, $A U C_{0-i n f}$ area under the plasma concentration-time curve extrapolated to infinity, $C_{\max }$ maximum concentration, $\lambda z$ elimination rate constant, $T_{1 / 2}$ half-life in terminal phase, $M R T_{0-i n f}$. mean residence time extrapolated to infinity, $V d_{s s}$ volume of distribution at steady state, $C L$ total body clearance, $C T$ chemotherapy with cisplatin and paclitaxel

* Values are the no. of patients who received BNP7787 alone/no. of patients who had BNP preceding combination of paclitaxel and cisplatin

$* *$ Mean \pm SD

mean $\mathrm{Vd}_{\mathrm{ss}}$ for BNP7787 alone and in combination with chemotherapy were $8.45-17.78$ and 9.06-21.72, respectively.

\section{Clinical recommended dose}

Following careful review of the phase I trial data from this and other studies, a BNP7787 dose of $18.4 \mathrm{~g} / \mathrm{m}^{2}$ was selected as the clinically recommended dose based on a balance of efficacy and safety observations. The recommended dose was not based on the maximum tolerated dose since no dose-limiting toxicities were observed with the administration of BNP7787 alone or in combination with chemotherapy at any of the dose levels tested.

The selection of $18.4 \mathrm{~g} / \mathrm{m}^{2}$ as the recommended phase II dose was based on the balance of toxicity, higher grades of neurotoxicity and nephrotoxicity observed with lower doses of BNP7787 (e.g., 4.1-12.3 g/m²), and the increased frequency of local IV site discomfort observed at higher doses of BNP7787 (above $27.6 \mathrm{~g} / \mathrm{m}^{2}$ ).

We also note that the molar ratio of the doses of BNP7787 $18.4 \mathrm{~g} / \mathrm{m}^{2}$ and paclitaxel $175 \mathrm{mg} / \mathrm{m}^{2}$ and cisplatin $75 \mathrm{mg} / \mathrm{m}^{2}$ are 275:1 and 226:1, respectively. These molar ratios of the drugs are consistent with dose molar ratios that have demonstrated neuroprotection and nephroprotection in preclinical studies.

\section{Response}

Twenty-one patients were assessed for objective tumor response. Although there was no complete response, nine patients attained a partial response, with an overall response rate of $43 \%$. Stable disease was observed in eight patients $(38 \%)$. One patient was non-evaluable because of atelectasis of the lung surrounding and obscuring the primary marker lesion. The remaining three patients $(14 \%)$ had progressive disease. In 10 patients with prior chemotherapy, four (40\%) achieved a partial response. Among 11 patients with no prior chemotherapy, five $(46 \%)$ had a partial response.

\section{Discussion}

This trial demonstrated that administration of BNP7787 at doses of $4.1 \mathrm{~g} / \mathrm{m}^{2}$ up to $41.0 \mathrm{~g} / \mathrm{m}^{2}$ alone or in combination with paclitaxel and cisplatin was safe and feasible. Generally, 
Table 6 Pharmacokinetic parameters of mesna following administration of BNP7787 alone and BNP7787 in combination with paclitaxel and cisplatin

\begin{tabular}{|c|c|c|c|c|c|c|c|}
\hline \multirow[t]{2}{*}{ Parameter } & \multirow[t]{2}{*}{ Treatment } & \multicolumn{6}{|c|}{ BNP7787 dose $\left(\mathrm{g} / \mathrm{m}^{2}\right)$} \\
\hline & & $4.1(n=3 / 3)^{*}$ & $8.2(n=6 / 5)$ & $12.3(n=4 / 4)$ & $18.4(n=3 / 3)$ & $27.6(n=3 / 3)$ & $41.0(n=3 / 3)$ \\
\hline \multirow[t]{2}{*}{$\operatorname{AUC}_{0-\mathrm{t}}(\mu \mathrm{g} \cdot \mathrm{h} / \mathrm{mL})$} & BNP alone & $27.80 \pm 9.67 * *$ & $80.92 \pm 25.01$ & $86.49 \pm 46.19$ & $163.26 \pm 71.90$ & $398.21 \pm 97.95$ & $565.25 \pm 183.38$ \\
\hline & $\mathrm{BNP}+\mathrm{CT}$ & $34.75 \pm 11.50$ & $78.97 \pm 28.84$ & $85.41 \pm 22.43$ & $153.19 \pm 32.24$ & $363.39 \pm 160.61$ & $421.30 \pm 153.04$ \\
\hline \multirow[t]{2}{*}{$\mathrm{AUC}_{0 \text {-inf. }}(\mu \mathrm{g} \mathrm{h} / \mathrm{mL})$} & BNP alone & $29.33 \pm 10.14$ & $81.96 \pm 25.29$ & $88.71 \pm 45.58$ & $164.97 \pm 71.13$ & $398.93 \pm 98.18$ & $566.32 \pm 183.20$ \\
\hline & $\mathrm{BNP}+\mathrm{CT}$ & $35.96 \pm 12.14$ & $80.47 \pm 28.19$ & $88.59 \pm 22.42$ & $155.99 \pm 31.82$ & $364.21 \pm 161.12$ & $421.81 \pm 153.04$ \\
\hline \multirow[t]{2}{*}{$\mathrm{C}_{\max }(\mu \mathrm{g} / \mathrm{mL})$} & BNP alone & $10.20 \pm 0.43$ & $19.84 \pm 2.37$ & $23.21 \pm 6.86$ & $47.30 \pm 13.64$ & $63.22 \pm 16.25$ & $82.29 \pm 2.48$ \\
\hline & $\mathrm{BNP}+\mathrm{CT}$ & $14.55 \pm 2.44$ & $21.70 \pm 2.19$ & $24.40 \pm 4.05$ & $42.15 \pm 1.91$ & $52.76 \pm 5.64$ & $62.75 \pm 4.79$ \\
\hline \multirow[t]{2}{*}{$\mathrm{T}_{\max }(\mathrm{h})$} & BNP alone & $0.84 \pm 0.16$ & $1.00 \pm 0.45$ & $1.25 \pm 0.28$ & $1.17 \pm 0.29$ & $1.82 \pm 0.59$ & $1.69 \pm 0.95$ \\
\hline & $\mathrm{BNP}+\mathrm{CT}$ & $0.58 \pm 0.14$ & $0.90 \pm 0.14$ & $0.96 \pm 0.12$ & $1.18 \pm 0.28$ & $1.82 \pm 0.60$ & $1.40 \pm 0.26$ \\
\hline \multirow[t]{2}{*}{$\mathrm{T}_{1 / 2}(\mathrm{~h})$} & BNP alone & $3.17 \pm 2.87$ & $4.59 \pm 0.52$ & $1.74 \pm 0.95$ & $1.59 \pm 1.11$ & $2.66 \pm 0.04$ & $2.70 \pm 0.21$ \\
\hline & $\mathrm{BNP}+\mathrm{CT}$ & $2.96 \pm 2.88$ & $2.96 \pm 1.56$ & $1.87 \pm 1.10$ & $1.65 \pm 1.05$ & $2.75 \pm 0.10$ & $2.52 \pm 0.11$ \\
\hline \multirow[t]{2}{*}{$\lambda \mathrm{z}\left(\mathrm{h}^{-1}\right)$} & BNP alone & $0.36 \pm 0.26$ & $0.15 \pm 0.02$ & $0.46 \pm 0.17$ & $0.57 \pm 0.29$ & $0.26 \pm 0.00$ & $0.26 \pm 0.02$ \\
\hline & $\mathrm{BNP}+\mathrm{CT}$ & $0.40 \pm 0.25$ & $0.31 \pm 0.19$ & $0.44 \pm 0.17$ & $0.53 \pm 0.27$ & $0.25 \pm 0.01$ & $0.27 \pm 0.01$ \\
\hline \multirow[t]{2}{*}{$\mathrm{MRT}_{0-\mathrm{t}}(\mathrm{h})$} & BNP alone & $2.2 \pm 1.3$ & $3.1 \pm 0.4$ & $2.3 \pm 0.8$ & $2.1 \pm 0.5$ & $3.6 \pm 0.7$ & $3.8 \pm 0.7$ \\
\hline & $\mathrm{BNP}+\mathrm{CT}$ & $1.9 \pm 0.8$ & $2.6 \pm 0.9$ & $2.2 \pm 0.5$ & $2.2 \pm 0.6$ & $3.7 \pm 0.8$ & $3.7 \pm 0.8$ \\
\hline \multirow[t]{2}{*}{$\operatorname{MRT}_{0 \text {-inf. }}(\mathrm{h})$} & BNP alone & $2.91 \pm 1.75$ & $3.48 \pm 0.51$ & $2.48 \pm 0.71$ & $2.15 \pm 0.48$ & $3.67 \pm 0.73$ & $3.86 \pm 0.72$ \\
\hline & $\mathrm{BNP}+\mathrm{CT}$ & $2.32 \pm 1.11$ & $2.91 \pm 0.88$ & $2.47 \pm 0.46$ & $2.35 \pm 0.57$ & $3.77 \pm 0.78$ & $3.73 \pm 0.82$ \\
\hline
\end{tabular}

$A U C_{0-t}$ area under the plasma concentration-time curve up to last measurable point, $A U C_{0-i n f .}$ area under the plasma concentration-time curve extrapolated to infinity, $C_{\max }$ maximum concentration, $T_{\max }$ time to maximal concentration, $T_{1 / 2}$ half-life in terminal phase, $\lambda z$ elimination rate constant, $M R T_{0 \text {-inf. }}$ mean residence time extrapolated to infinity, $C T$ chemotherapy with paclitaxel and cisplatin

* Values are the no. of patients who received BNP alone/no. of patients who had BNP preceding combination of paclitaxel and cisplatin

** Mean \pm SD

adverse effects attributable to BNP7787 were very mild and reversible. No grade 2 or worse toxicity was observed at all dose levels, except for grade 2 skin rash observed at dose level 2, which resulted in termination of study treatment in that patient (Table 3). The only frequent adverse effect was the transient local discomfort at the infusion site of grade 1 up to $18.4 \mathrm{~g} / \mathrm{m}^{2}$ of BNP7787. At dose level 5 and 6 , which represented a BNP7787 dose of 27.6 and $41.0 \mathrm{~g} / \mathrm{m}^{2}$, all patients experienced transient local grade 1 discomfort at the iv site. This toxicity was to some degree, lessened by extending the infusion time from 30 to $45 \mathrm{~min}$. Other toxicities encountered at these higher dose levels included thirst (3 of 6 patients), facial flush (4 of 6 patients), and nasal obstruction ( 2 of 6 patients; Table 3 ). These adverse effects usually disappeared promptly after the end of infusion. The starting dose of $4.1 \mathrm{~g} / \mathrm{m}^{2}$ was based on aggregate GLP safety data in rats and dogs and by the calculation of a BNP7787: cisplatin $=50: 1$ molar ratio that was required for partial cisplatin nephroprotection in rats [7]. Dose-limiting toxicities were not observed at any dose level, including the highest tested dose level of $41.0 \mathrm{~g} / \mathrm{m}^{2}$ as defined in the protocol. This dose level is far in excess for what is required for cytoprotection in non-clinical studies since the molar ratio of BNP7787:cisplatin at the BNP7787 $41.0 \mathrm{~g} / \mathrm{m}^{2}$ dose level was $503: 1$. The dose of $41.0 \mathrm{~g} / \mathrm{m}^{2}$ of BNP7787 was well tolerated by NSCLC patients, and the overall safety profile in this study is consistent with prior phase I studies of paclitaxel followed by BNP7787 administered prior to cisplatin in patients with advanced solid malignancies $[3,19]$.

BNP7787 pharmacokinetics was similar to those reported in a previous human phase I study [3, 21]. After cessation of infusion, the BNP7787 curves showed singleexponential decay (Fig. 1). In accordance with the report by Verschraagen et al. $[3,21]$, with half-life times of $0.66-$ $1.67 \mathrm{~h}$ and $0.62-2.33 \mathrm{~h}$, the concentrations of the BNP7787 alone and in combination with cisplatin and paclitaxel declined in parallel, with identical slopes (Fig. 1a, b). Mean BNP7787 $\mathrm{C}_{\max }$ and $\mathrm{AUC}_{0 \text {-inf }}$ increased linearly with dose in the dose ranges administered (Table 5). Verschraagen et al. $[3,21]$ also reported human pharmacokinetics of mesna following administration of IV BNP7787. Mesna formation following BNP7787 administration observed is consistent with extravascular non-enzymatic and enzymatic metabolism of BNP7787 [16]. Mesna is reported to be more reactive with hydrated cisplatin when compared with its disulfide BNP7787 [8, 9, 12, 22]. Mesna appeared in plasma after the start of BNP7787 infusion, which is consistent with extravascular metabolism and preservation of the law of mass action balance relationship of disulfide to 

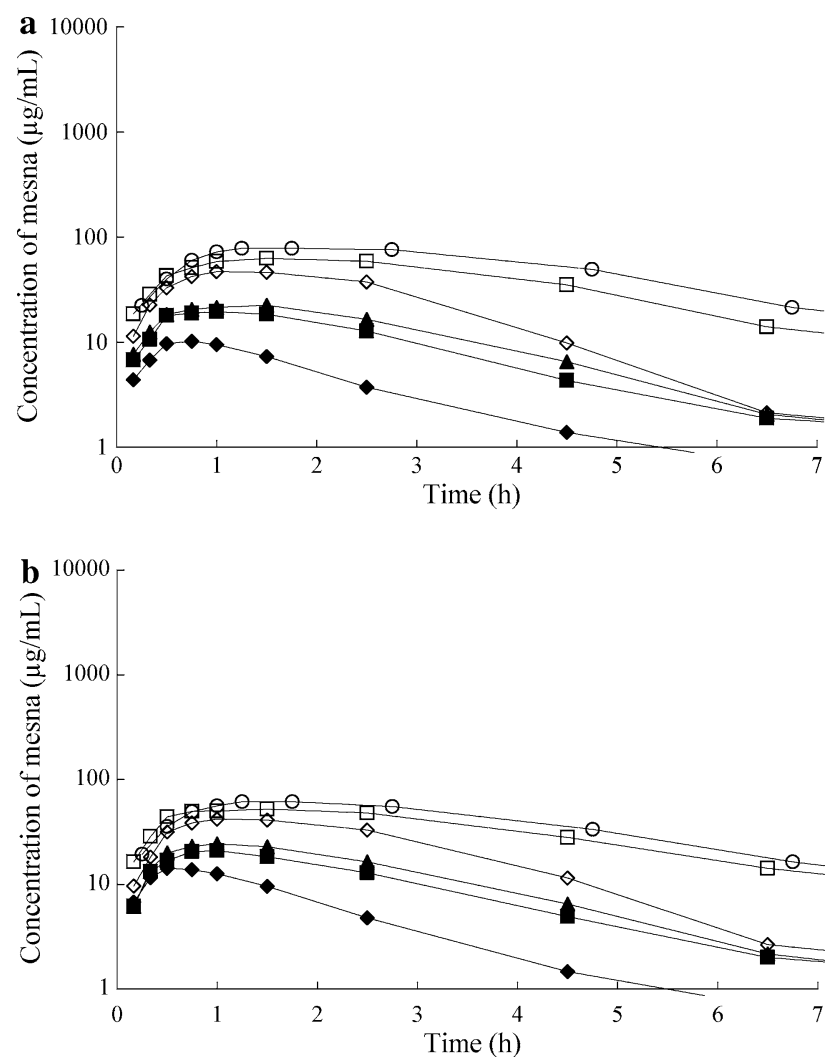

Fig. 2 Plasma concentration-time curves of the active metabolite, mesna in patients receiving BNP7787 treatment at dose of $4.1 \mathrm{~g} / \mathrm{m}^{2}$ (filled diamond), $8.2 \mathrm{~g} / \mathrm{m}^{2}$ (filled square), $12.3 \mathrm{~g} / \mathrm{m}^{2}$ (filled triangle), $18.4 \mathrm{~g} / \mathrm{m}^{2}$ (open diamond), $27.6 \mathrm{~g} / \mathrm{m}^{2}$ (open square) and $41.0 \mathrm{~g} / \mathrm{m}^{2}$ (open circle) in alone (a) and in combination with paclitaxel and cisplatin (b). Each point represents the mean of patients. Infusion time was $30 \mathrm{~min}$ except for three patients at the highest dose level of $41.0 \mathrm{~g} / \mathrm{m}^{2}$

thiol in plasma under physiological conditions [9]. The metabolite-to-BNP7787 ratio of $\mathrm{C}_{\max }$ was about $2.2 \%$, which is predicted by the free thiol hypothesis and prior studies [9]. Although plasma concentrations of BNP7787 began to decline at the end of the infusion, those of the metabolite increased initially and the maximal plasma levels were reached from $30 \mathrm{~min}$ to $1 \mathrm{~h}$ after the end of the infusion, with the half-life of from 0.88 to $6.45 \mathrm{~h}$ and from 0.90 to $6.28 \mathrm{~h}$ for BNP7787 alone and in combination with chemotherapy, respectively. The administration of paclitaxel and cisplatin in this study did not show any observable effect on BNP7787 pharmacokinetics when compared to the observed pharmacokinetics of single agent administration of BNP7787. This observation further supports prior studies demonstrating that BNP7787 is compatible and feasible with regard to co-administration of paclitaxel and cisplatin when all drugs are administered on this schedule and by the iv route (Table 5) [3, 7-9, 11, 20].

Of 21 patients, the overall response rate of $43 \%$ was observed during this phase I trial in patients with advanced
NSCLC although no patients showed a complete response. The combination of paclitaxel and cisplatin in advanced NSCLC patients with no prior chemotherapy is historically reported to produce response rates between 21 and $41 \%$ $[1,6,16-18]$. A response rate of $46 \%$ in previously untreated patients observed here appears to be in the upper range of the reported trials in NSCLC with this regimen, and the co-administration of BNP7787 did not appear to interfere with the antitumor activity of paclitaxel and cisplatin in patients with advanced NSCLC. It is notable that four of 10 patients (40\%) patients attained a PR in patients who had received prior chemotherapy, supporting further evaluation of BNP7787 in additional clinical studies. The number of patients in this study is too small to draw any valid conclusion about the ultimate clinical activity of this regimen, and it will be investigated in future studies.

In conclusion, this study confirmed that administration of a recommended BNP7787 dose level of $18.4 \mathrm{~g} / \mathrm{m}^{2}$ in combination with paclitaxel and cisplatin is safe to use to evaluate for potential efficacy in future studies in patients. The more common and non-dose-limiting BNP7787related toxicities included local transient discomfort at the infusion site, facial flush, thirst, and nasal obstruction were very mild, and usually not greater than grade 2 . A randomized multicenter phase III trial of paclitaxel, BNP7787 and cisplatin was subsequently initiated to determine the safety and efficacy of BNP7787 for the prevention of paclitaxeland cisplatin-induced neurotoxicity, as well as other toxicities and also to evaluate the potential efficacy of BNP7787 in patients with advanced NSCLC.

Acknowledgments We acknowledge Ms. Erika Ramirez at BioNumerik Pharmaceuticals Inc. for her skillful editorial assistance in the preparation of this manuscript.

Conflict of interest statement Frederick Hausheer, MD, FACP, is a significant shareholder in BioNumerik Pharmaceuticals Inc. the originator of Tavocept, and is in a leadership and management position in this company. The funding source of this trial is ASKA Pharmaceuticals Co., which is in a Joint Venture relationship with BioNumerik Pharmaceuticals Inc. in Japan. Other authors indicated no potential conflicts of interest.

Open Access This article is distributed under the terms of the Creative Commons Attribution Noncommercial License which permits any noncommercial use, distribution, and reproduction in any medium, provided the original author(s) and source are credited.

\section{References}

1. Bonomi P, Kim K, Fairclough D, Cella D, Kugler J, Rowinsky E, Jiroutek M, Johnson D (2000) Comparison of survival and quality of life in advanced non-small-cell lung cancer patients treated with two dose levels of paclitaxel combined with cisplatin versus etoposide with cisplatin: results of an Eastern Cooperative Oncology Group trial. J Clin Oncol 18:623-631 
2. Boven E, Verschraagen M, Hulscher TM, Erkelens CA, Hausheer FH, Pinedo HM, van der Vijgh WJ (2002) BNP7787, a novel protector against platinum-related toxicities, does not affect the efficacy of cisplatin or carboplatin in human tumour xenografts. Eur J Cancer 38:1148-1156

3. Boven E, Westerman M, van Groeningen CJ, Verschraagen M, Ruijter R, Zegers I, van der Vijgh WJ, Giaccone G (2005) Phase I and pharmacokinetic study of the novel chemoprotector BNP7787 in combination with cisplatin and attempt to eliminate the hydration schedule. Br J Cancer 92:1636-1643

4. Cavalletti E, Cavaletti G, Tredici G, Oggioni N, Spinelli S, Reddy D, Zhao M, Wu M, Hauseheer F (1999) Oral and intravenous BNP7787 protects against paclitaxel-mediated neurotoxicity in Wistar rats. Proc Am Soc Cancer Res 40:398

5. Fossella F, Pereira JR, von Pawel J, Pluzanska A, Gorbounova V, Kaukel E, Mattson KV, Ramlau R, Szczesna A, Fidias P, Millward M, Belani CP (2003) Randomized, multinational, phase III study of docetaxel plus platinum combinations versus vinorelbine plus cisplatin for advanced non-small-cell lung cancer: the TAX 326 study group. J Clin Oncol 21:3016-3024

6. Giaccone G, Splinter TA, Debruyne C, Kho GS, Lianes P, van Zandwijk N, Pennucci MC, Scagliotti G, van Meerbeeck J, van Hoesel Q, Curran D, Sahmoud T, Postmus PE (1998) Randomized study of paclitaxel-cisplatin versus cisplatin-teniposide in patients with advanced non-small-cell lung cancer. The European Organization for Research and Treatment of Cancer Lung Cancer Cooperative Group. J Clin Oncol 16:2133-2141

7. Hausheer FH, Kanter P, Cao S, Haridas K, Seetharamulu P, Reddy D, Petluru P, Zhao M, Murali D, Saxe JD, Yao S, Martinez N, Zukowski A, Rustum YM (1998) Modulation of platinum-induced toxicities and therapeutic index: mechanistic insights and first- and second-generation protecting agents. Semin Oncol 25:584-599

8. Hausheer FH, Kanter P, Rustum Y, Cao S, Haridas K, Reddy D, Seetharamulu P, Zhao M, Yao S, Pavankumar P, Murali D (2001) BNP7787: a novel antitumor potentiating drug which protects against cisplatin and carboplatin toxicities. Proc Am Soc Cancer Res 38:311

9. Hausheer FH, Kochat H, Parker AR, Ding D, Yao S, Hamilton SE, Petluru PN, Leverett BD, Bain SH, Saxe JD (2003) New approaches to drug discovery and development: a mechanism-based approach to pharmaceutical research and its application to BNP7787, a novel chemoprotective agent. Cancer Chemother Pharmacol 52(Suppl 1):S3-S15

10. Hausheer FH, Schilsky RL, Bain S, Berghorn EJ, Lieberman F (2006) Diagnosis, management, and evaluation of chemotherapyinduced peripheral neuropathy. Semin Oncol 33:15-49

11. Hausheer FH, Shanmugarajah D, Leverett BD, Chen X, Huang Q, Kochat H, Petluru PN, Parker AR (2010) Mechanistic study of BNP7787-mediated cisplatin nephroprotection: modulation of gamma-glutamyl transpeptidase. Cancer Chemother Pharmacol 65:941-951
12. Leeuwenkamp OR, Neijt JP, van der Vijgh WJ, Pinedo HM (1991) Reaction kinetics of cisplatin and its monoaquated species with the modulating agents (di)mesna and thiosulphate. Eur J Cancer 27:1243-1247

13. Miller AB, Hoogstraten B, Staquet M, Winkler A (1981) Reporting results of cancer treatment. Cancer 47:207-214

14. Mountain CF (1997) Revisions in the international system for staging lung cancer. Chest 111:1710-1717

15. Pfister DG, Johnson DH, Azzoli CG, Sause W, Smith TJ, Baker S Jr, Olak J, Stover D, Strawn JR, Turrisi AT, Somerfield MR (2004) American Society of Clinical Oncology treatment of unresectable non-small-cell lung cancer guideline: update 2003. J Clin Oncol 22:330-353

16. Rosell R, Gatzemeier U, Betticher DC, Keppler U, Macha HN, Pirker R, Berthet P, Breau JL, Lianes P, Nicholson M, Ardizzoni A, Chemaissani A, Bogaerts J, Gallant G (2002) Phase III randomised trial comparing paclitaxel/carboplatin with paclitaxel/cisplatin in patients with advanced non-small-cell lung cancer: a cooperative multinational trial. Ann Oncol 13:1539-1549

17. Sakai H, Yoneda S, Tamura T, Nishiwaki Y, Yokoyama A, Watanabe K, Saijo N (2001) A phase II study of paclitaxel plus cisplatin for advanced non-small-cell lung cancer in Japanese patients. Cancer Chemother Pharmacol 48:499-503

18. Schiller JH, Harrington D, Belani CP, Langer C, Sandler A, Krook J, Zhu J, Johnson DH (2002) Comparison of four chemotherapy regimens for advanced non-small-cell lung cancer. N Engl J Med 346:92-98

19. Schilsky RL, Desai A, Creaven P, Berghorn E, Ratain M, Hauseheer F (2003) BNP7787 permits safe administration of paclitaxel and cisplatin without iv hydration. Proc Am Soc Clin Oncol 22:594

20. Shanmugarajah D, Ding D, Huang Q, Chen X, Kochat H, Petluru PN, Ayala PY, Parker AR, Hausheer FH (2009) Analysis of BNP7787 thiol-disulfide exchange reactions in phosphate buffer and human plasma using microscale electrochemical high performance liquid chromatography. J Chromatogr B Analyt Technol Biomed Life Sci 877:857-866

21. Verschraagen M, Boven E, Ruijter R, van der Born K, Berkhof J, Hausheer FH, van der Vijgh WJ (2003) Pharmacokinetics and preliminary clinical data of the novel chemoprotectant BNP7787 and cisplatin and their metabolites. Clin Pharmacol Ther 74:157169

22. Verschraagen M, Kedde MA, Hausheer FH, Van Der Vijgh WJ (2003) The chemical reactivity of BNP7787 and its metabolite mesna with the cytostatic agent cisplatin: comparison with the nucleophiles thiosulfate, DDTC, glutathione and its disulfide GSSG. Cancer Chemother Pharmacol 51:499-504

23. Wolf S, Barton D, Kottschade L, Grothey A, Loprinzi C (2008) Chemotherapy-induced peripheral neuropathy: prevention and treatment strategies. Eur J Cancer 44:1507-1515 